\title{
The application of inverter and PLC in fire extinguisher in welding device
}

\author{
BiaoZhou \\ College of Mechanical Engineering, Quzhou University, Quzhou 324000,China \\ 271584089@qq.com
}

Keywords: Fire extinguisher; Straight; Girth; Inverter; PLC; Automatic control

\begin{abstract}
There are many types of fire extinguishers, cylinder size is larger, the paper introduces a kind of using frequency converter and PLC control can achieve the fire extinguisher of longitudinaland girth welding device and its working principle of the hardware and software design, At the same time put forward the method to realize the change of multiple types of welding . Put forward the longitudinal and girth welding automatic machine widely used and versatile.
\end{abstract}

\section{Introduction}

With the development of manufacturing industry is now increasingly higher level, labor costs are increasing, How to fully improve the efficiency and reduce the manufacturing cost has become the inevitable choice of enterprises are now. Ring straight seam welding device is a commonly used device for welding in manufacturing of pressure vessel, in a widely application aerospace, ship manufacturing,automobile and fire extinguishers in the manufacturing field. The use of PLC control system for cylinder of longitudinal and girth welding has the advantages of high efficiency, good repeatability, especially to fully reduce therequirements of technical workers.s.The welding machine on the market are generally in simple straight seam welded or girth weldingmode. Using these two kinds of welding machine is the high cost and increase productproduction process. In order to overcome these shortcomings, we use the frequency converter and PLC transform the traditional machine tools, implementation of longitudinal and girth weldingclamping once completed at the same time, it has the advantages of high reliability, strong practicability and flexibility .

\section{The Automatic Welding system composed of Longitudinal and Girth}

The composition of automatic machine of the system is mainly composed of 3 welding machine andstraight running device and welding special machine tool. 3 welding machine can choose DIR-350series type, By machine tool headstock, bed andsupport, weldingtorch adjusting ,rack, shield, pneumaticparts, control box, transducer and electrical control box and other components, the welding machine adopts PLC industrial microprocessor, optical coupler, the electronic induction sensor to realize automatic welding process control. The clamping and loosening of the workpiece, the torch forward and exit, open and close all adopt pneumatic device to control the completion of protective equipment. According to the motor speed $n=(1-s) 60 f / p$, through the inverter speed control of the motor, to achieve the type of welding equipment on the $4 \mathrm{KG}, 5 \mathrm{KG}, 6 \mathrm{KG}, 7 \mathrm{KG}, 8 \mathrm{KG}$ series of fire extinguisher complete automation middle straight seam welding andthe lower end of the girth welding, high production efficiency, improve system power factor increase the useful power grid, the weld quality in line with national standards. System components as shown in figure 1.

\section{Principle and Connection Mode of work}

Working principle. According to different types of cylinder select dies of different sizes and will be after the initial foldingplate installed in the mold on the spindle concentric. The start 
button on the PLC under the action of the control system inthe clamping devicefor clamping workpiece, straight welding start according to the procedures set distance complete straight line welding, 2 second delay in straight line circular seam welding torch is reset, a double gun began to run to the specified location, after carrying the spindle fire extinguisher begins to rotate, the 2 ring seam welding machine at start welding fire extinguisher on the girth, after the completion of welding, manual unloading, the system to complete the 1 operation cycle, return to the initial position, its work process is shown in figure 2. According to the control requirements, we choose Mitsubishi inverter FR-E740 and PLC Mitsubishi series FX2N-48MR.

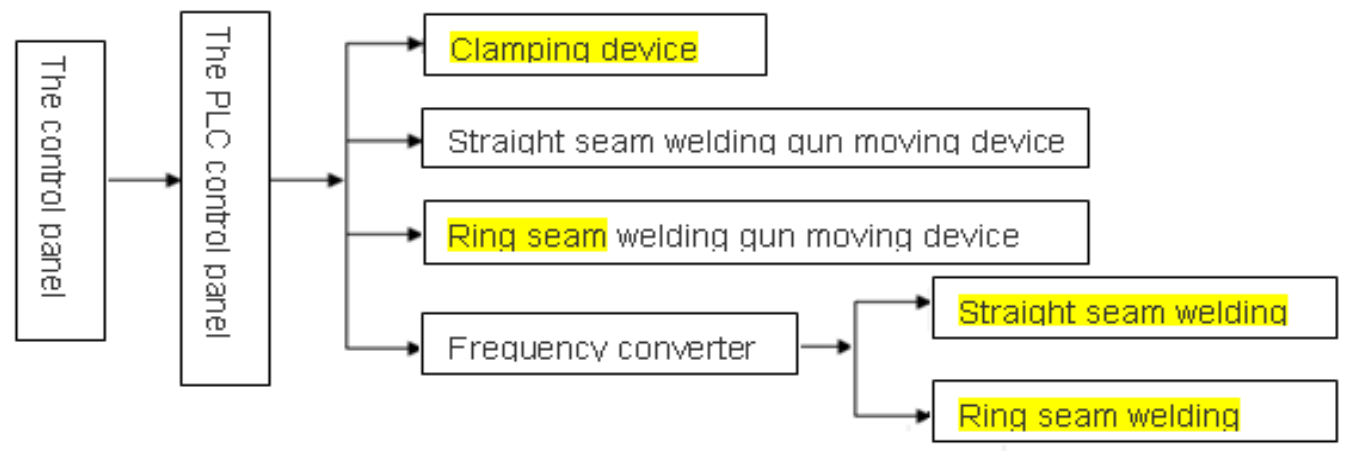

Fig.1 System structure diagram



Fig.2 Work flow chart

\section{The hardware connection}

1) The main circuit is connected . Fire extinguisher for different thickness so different types of welding current and time are not the same, so we use the frequency converter to realize the regulation to ensure the welding quality ofwelded M1 motor and spindle motor M2 speed. The main circuit as shown in figure 3. Movement speed by inverter control straight seam welding torch, guarantee the quality of straight seam welding,the girth welding inverter control through the rotation speed of the spindle motor of machine tool toensure the girth welding quality.

2) PLC input, output address assignment. Mitsubishi series FX2N-48MR-D input and output port allocation table as shown in Table 1 


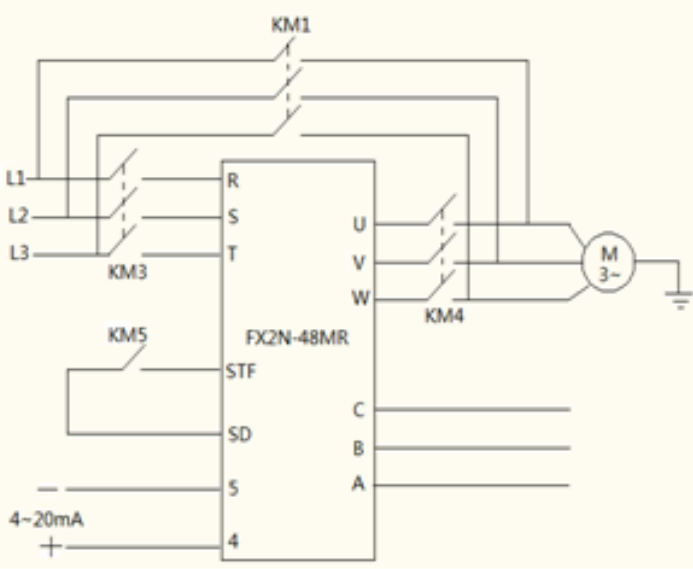

Fig.3 The main circuit wiring diagram

\begin{tabular}{|l|l|l|l|l|}
\hline Input & Relay & Output & Relay & Explain \\
\hline SB1 & X0 & Y0 & KM1 & Motor start \\
\hline SB2 & X1 & Y1 & KM2 & Motor start lamp \\
\hline C & X2 & Y2 & KM3 & $\begin{array}{l}\text { Frequency } \\
\text { corversion }\end{array}$ \\
\hline B & X3 & Y3 & KM4 & $\begin{array}{l}\text { Frequency } \\
\text { corversion }\end{array}$ \\
\hline A & X4 & Y4 & KM5 & $\begin{array}{l}\text { Using frequency } \\
\text { corverter }\end{array}$ \\
\hline & & Y5 & KM6 & $\begin{array}{l}\text { Straight seam } \\
\text { welded indcator }\end{array}$ \\
\hline & & Y6 & KM7 & $\begin{array}{l}\text { Girth } \\
\text { welding indicator }\end{array}$ \\
\hline & & Y7 & KM8 & Fault indicator \\
\hline
\end{tabular}

Table $.1 \mathrm{I} / \mathrm{O}$ port allocation table

3) The PLC input, the output terminal. PLC output connection as shown in figure 4.

PLC software. System design is based on the logic flow diagram design requirements, use ladderlanguage to achieve. Welding of $4 \mathrm{~kg}$ cylinder procedure as shown in figure 5. The specific program according to the ladder diagram to write.

In the device software, use the timer to control spindle running time, by the timer, finish straight and girth welding or segmental welding cycle. Press the SB1 button, first start atpower frequency welding way, start indicator lights, KM3 and KM4 on delay 2S, the motor is enter the working state of variable frequency, drive the welding torch according to set straight seam welding speed operation finish straight seam welding, and the position sensor to provide speed anddisplacement signal of welding torch moving in straight seam welding, at the same time, output girth welding signal. The signals are processed into $4 \sim 20 \mathrm{~mA}$ current analog signal into the frequency converter, the 4 and the 5 end, when straight after welding to girth welding welding speed required to complete the ring seam. Thus a one-time completion of the cylinder body of longitudinal and girth welding task. At the same time also reached the production process is simple, the purpose of saving energy. When the inverter fault, B and C two section of the normally closed switch off, the inverter to stopwork; the normally open switch closed ends B and C, the fault indicator light, to maintenance and troubleshooting.

When the inverter fault, B and C of the normally closed switch is disconnected, the inverter to stop working; at the same time, B and C of the normally open switch is closed, the fault indicator light,waiting for troubleshooting.Conclusion.

The longitudinal and girth welding is wide application field, especially in the welding process of pressure vessel. Using frequency converter and PLC control of longitudinal and girth welding device is complete functions, reliable work, simple operation, convenient. It can reduce the technical level of workers and the cost of labor. 

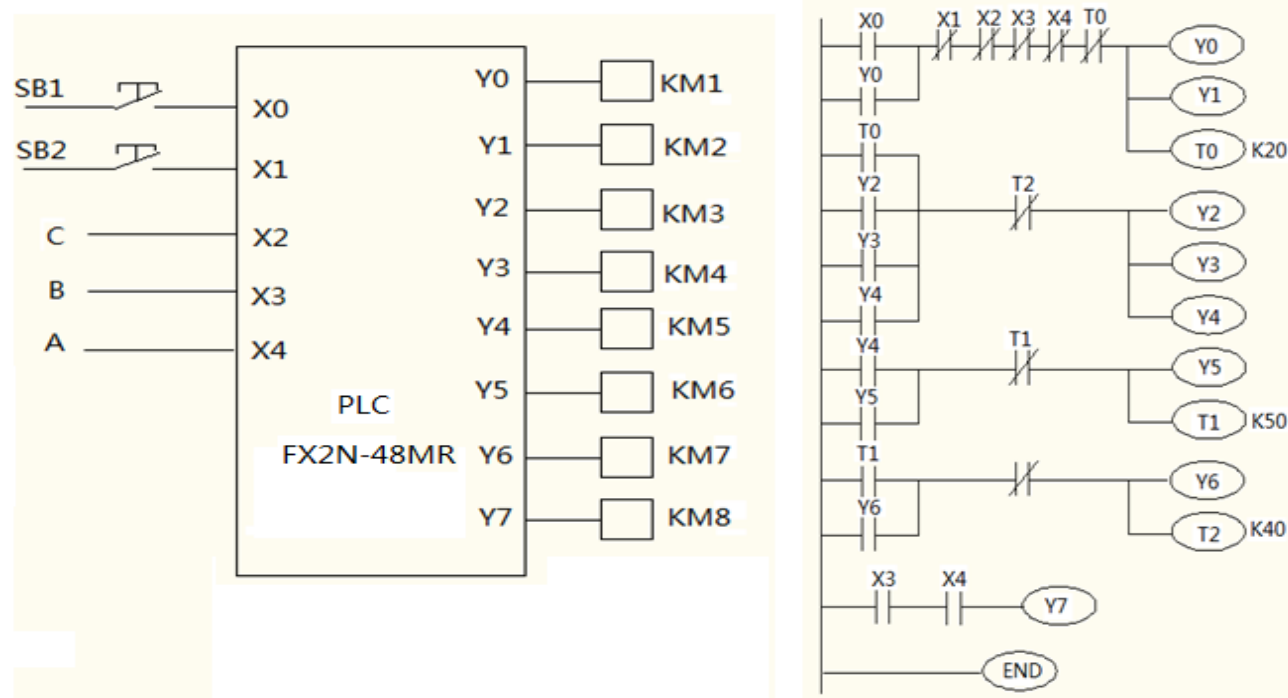

Fig. 4 PLC Input and output wiring diagram

Fig. 5 PLC ladder diagram

\section{Acknowledgement}

This work is by Zhejiang Province Bureau of Quzhou city science and technology project of China(20121050),Zhejiang Province Education Department Research Project s of China (Y201225648).

\section{References}

[1] Welding Handbook: welding structure of "S" (Third Edition). Beijing: Mechanical Industry Press,2008,1 (1).

[2] Wu Li electric control and PLC technology Ml. Beijing: Mechanical Industry Press, 2009,1 (1)

[3] Wang Zhankui, Wang Lin. Contemporary electrical energy saving inverter [J]. electric technologyleader in 2007 (8): 26-28

[4] Zhang Yanbin. Motor variable speed graphic "Ml. Beijing: China electric power press, 2003

[5] Chang Xiaoling. The electric control system and programmable controller Ml. Beijing:

Mechanical Industry Press, 2004 (1): 172-176

[6] is wearing a flat. The programmable controller technology and application "Ml.

Beijing:Mechanical Industry Press in 2004 (1): 141-166 